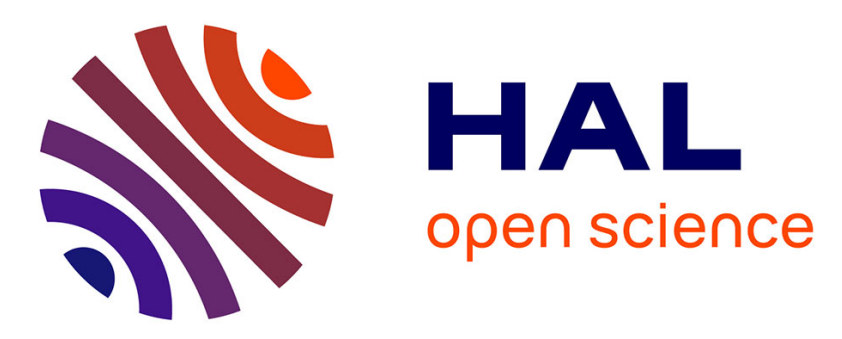

\title{
A compact circularly-polarized array based on superdirective elements
}

\author{
Abdullah Haskou, Ala Sharaiha, Sylvain Collardey
}

\section{To cite this version:}

Abdullah Haskou, Ala Sharaiha, Sylvain Collardey. A compact circularly-polarized array based on superdirective elements. IEEE Middle East Conference on Antennas and Propagation (MECAP), Sep 2016, Beirut, Lebanon. pp.1 - 3, 10.1109/MECAP.2016.7790082 . hal-01421335

\section{HAL Id: hal-01421335 \\ https://hal.science/hal-01421335}

Submitted on 28 Dec 2016

HAL is a multi-disciplinary open access archive for the deposit and dissemination of scientific research documents, whether they are published or not. The documents may come from teaching and research institutions in France or abroad, or from public or private research centers.
L'archive ouverte pluridisciplinaire HAL, est destinée au dépôt et à la diffusion de documents scientifiques de niveau recherche, publiés ou non, émanant des établissements d'enseignement et de recherche français ou étrangers, des laboratoires publics ou privés. 


\title{
A Compact Circularly-Polarized Array Based on Superdirective Elements
}

\author{
Abdullah Haskou, Ala Sharaiha and Sylvain Collardey \\ IETR UMR CNRS 6164- Université de Rennes 1, Rennes, France \\ Corresponding author email: abdullah.haskou@univ-rennes1.fr
}

\begin{abstract}
In this paper, a new strategy for designing compact Circularly-Polarized (CP) arrays is proposed. This approach consists of using small parasitic superdirective arrays as unit elements. An array is designed for $866 \mathrm{MHz}$ RFID band and a parametric analysis on the inter-element distance is performed to highlight the trade-offs between the antenna- dimensions, -directivity and radiation efficiency. For total dimensions of $220 \times 220 \times 25.8 \mathrm{~mm}^{3}(0.58 \lambda \times 0.58 \lambda \times 0.075 \lambda)$, the array has a CP directivity of $10.3 \mathrm{dBic}$ and a radiation efficiency of $38.5 \%$.
\end{abstract}

Keywords-Superdirective arrays, parasitic elements, circular polarization.

\section{INTRODUCTION}

Novel wireless technologies require increasingly compact antennas. However, conventional arrays lead to a significant increase in their size. Meanwhile, in superdirective arrays the unit-elements are put very closely together and their excitation coefficients are controlled to achieve the maximum directivity (in the end-fire direction) predicted by Uzkov [1]. Recently, there has been a renewed interest in superdirective arrays and in particular electrically small ones [2]-[11]. In this paper, we propose a new strategy for designing compact CircularlyPolarized (CP) arrays by using small superdirective arrays as unit-elements. The constraints including the maximum directivity, the efficiency, the antenna dimensions are studied. Results are validated through the realization and measurement of a $2 \times 2$ array. ${ }^{1}$

\section{ARRAY GEOMETRY AND PARAMETRIC StUdy}

In [10] a design methodology for superdirective arrays was detailed. It was shown that, by exciting one element and loading the others, the same excitation coefficients, and hence the same directivity radiation pattern, as in the fully driven array can be achieved. This method was used in [11] to design a two-element array for $866 \mathrm{MHz}$ RFID band. The unit-element used in the array is a short-circuited half loop antenna [8]. In the array, one element was excited while the other was loaded with a capacitor of $3.3 p F$. The antenna had a size factor of $k a=1.1$ and it had a simulated (HFSS [12]) total ditrectivity of $7 d B i$ and radiation efficiency of $43.4 \%$. Four elements of this array are integrated in $2 \times 2$ planar CP array (using the classical sequential rotation method) as shown in Fig. 1(a). The four elements are excited with phases of $0,90^{\circ}, 180^{\circ}$ and $270^{\circ}$ to achieve a Left-Hand

\footnotetext{
${ }^{1}$ This work was done with the funding of the French National Research Agency as part of the project "SOCRATE" and the support of the "Images et Reseaux" cluster of Brittany region, France.
}

Circular-Polarization (LHCP). It should be noticed that these excitations can be reversed to achieve Right-Hand CircularPolarization (RHCP). The spacing between the elements $d$ (calculated as a straight line between the excitation ports as shown in Fig. 1(a)) is changed from $10.1 \mathrm{~cm}$ to $27.6 \mathrm{~cm}$. Fig. 1(b) shows the antenna maximum LHCP directivity and the efficiency as a function of the distance. It can be noticed that as the distance increases the coupling effect decreases and the achieved directivity increases till it reaches its maximum value around $0.5 \lambda$ where it starts decreasing again. We can also note that as the distance increases the radiation efficiency decreases and it reaches its minimum when the maximum directivity occurs. Fig. 1(c) shows the antenna Half Power BeamWidth (HPBW) and CP aperture for an Axial Ratio $(A R)<3 d B$. As it can be noticed, $\mathrm{CP}$ aperture is always higher than the the HPBW. Moreover, AR is lower than $1 d B$ in the entire HPBW.

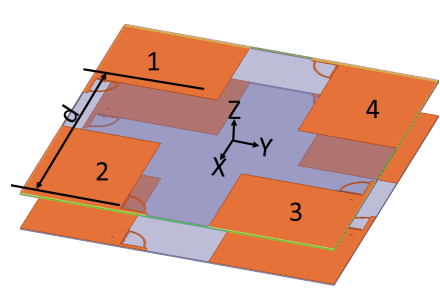

(a)

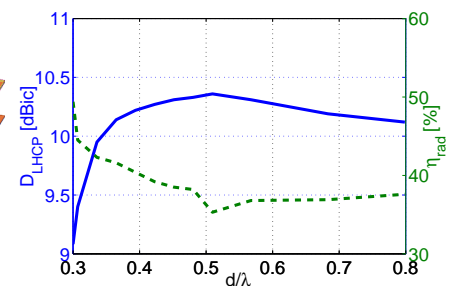

(b)

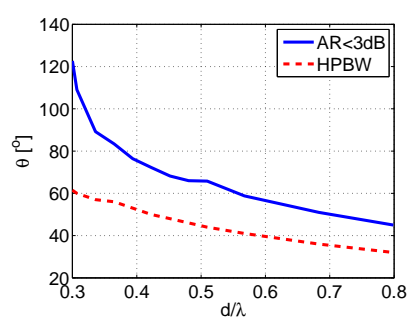

(c)

Fig. 1. Planar CP array simulated parameters as a function of the separation. (a) Geometry, (b) LHCP directivity and radiation efficiency and (c) HPBW and CP aperture.

\section{Simulation AND EXPERIMENTAL RESUlts}

A prototype of the antenna was fabricated and measured for a distance of $15.6 \mathrm{~cm} \approx 0.45 \lambda$ (Fig. 2(a)). Two ZX10-2$20+$ power dividers $\left(0,180^{\circ}\right)[13]$, a hybrid coupler $\left(0,90^{\circ}\right)$ from KDI/triangle [14], and four $30 \mathrm{~cm}$-long UFL cables [15] are used for the feeding system. Fig. 2(b) shows the antenna input reflection coefficient magnitude in $\mathrm{dB}$. The antenna has a 
simulated/measured resonance frequency of $866 / 879.8 \mathrm{MHz}$ (a frequency shift of $1.6 \%$ ). The antenna with the feeding system is well matched in all the observed band. This is mainly due to the losses in the feeding system. The antenna measured LHCP directivity given in Fig. 2(c) shows it increases till it reaches its maximum value of $10 \mathrm{dBic}$ at the resonance frequency then it starts decreasing again. The measured AR is also minimal around the resonance frequency. The antenna has a measured $\mathrm{CP}$ bandwidth $(A R<3 d B)$ of $21 \mathrm{MHz}$. Fig. 3(a) shows the antenna 3D LHCP directivity radiation pattern. It can be observed that the measured result is in a good agreement with the simulated one. The antenna has a simulated/ measured directivity of $10.3 / 10 \mathrm{dBic}$ in broadside direction (oZ). The antenna cross-polar (RHCP) 3D directivity radiation pattern is given in Fig. 3(b). The measured result is in acceptable agreement with the simulated one. The antenna 2D main- and cross-polar -directivity radiation patterns are given in Fig. 4. It can be noticed that the measured results in the main-polar are in a good agreement with the simulated ones. The simulated/ measured HPBW in $\mathrm{E}$ (XoZ) and $\mathrm{H}$ (YoZ) planes are respectively $48 / 45^{\circ}$ and $40.3 / 50.6^{\circ}$ and FBR is $40.3 / 19.8 d B$. The small difference in the cross-polar levels is mainly due to the measurement environment (the feeding system and the support). The antenna has a simulated radiation efficiency of $38.5 \%$ and reveals a measured one of about $40 \%$ after compensating the losses in the feeding system.

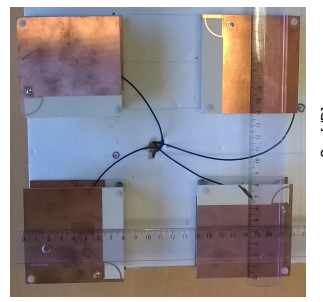

(a)

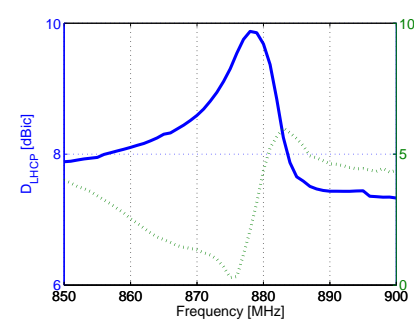

(c)

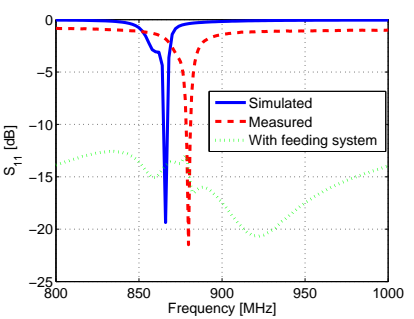

(b)

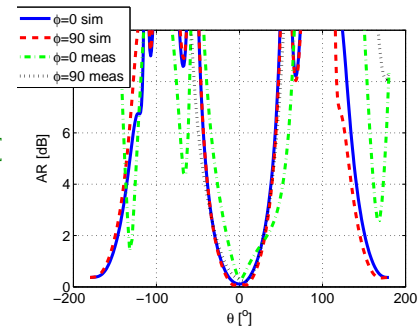

(d)
Fig. 2. Planar CP array with $d=15.6 \mathrm{~cm}$. (a) Fabricated prototype, (c) input reflection coefficient magnitude in $\mathrm{dB}$, (d) measured LHCP directivity and $\mathrm{AR}$ as a function of the frequency and (e) AR.

\section{CONCLUSION}

In this paper, a new design approach for compact $\mathrm{CP}$ arrays was presented. This approach consisted of using small parasitic superdirective arrays as unit elements. An array of total dimensions of $0.58 \lambda \times 0.58 \lambda \times 0.075 \lambda$ having a LHCP directivity of $10.3 \mathrm{dBic}$ and a radiation efficiency of $38.5 \%$ was designed for RFID applications. The experimental results were in a good agreement with the simulated ones.

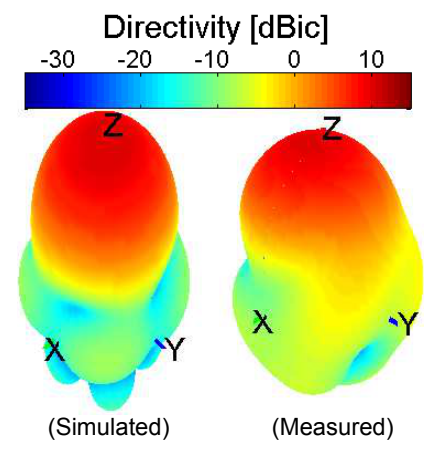

(a)

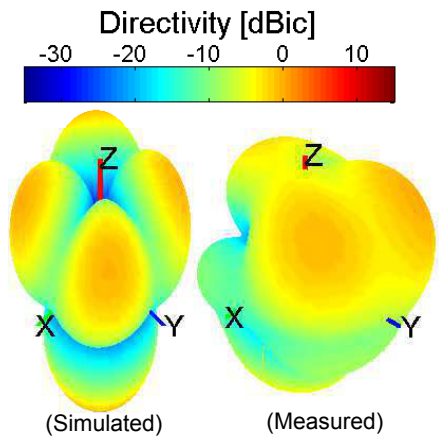

(b)
Fig. 3. Planar CP array 3D directivity radiation pattern for $\mathrm{d}=15.6 \mathrm{~cm}$. (a) Co-polar and (b) cross-polar.

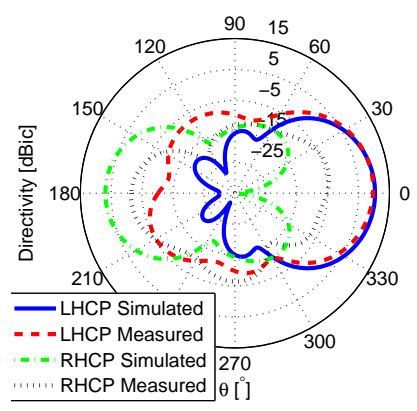

(a)

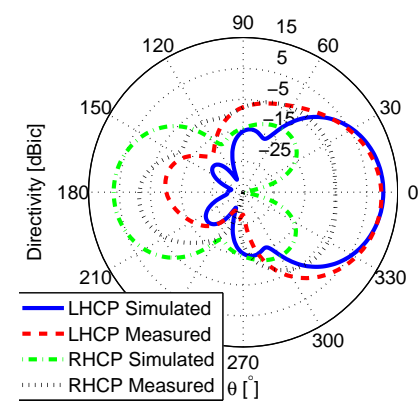

(b)
Fig. 4. Planar CP array $2 \mathrm{D}$ LHCP and RHCP directivity radiation pattern for $\mathrm{d}=15.6 \mathrm{~cm}$. (a) E plane and (b) $\mathrm{H}$ plane.

\section{REFERENCES}

[1] I. Uzkov, "An Approach to the Problem of Optimum Directive Antennae Design", Comptes rendues (Doklady) de l'académie des sciences de l'URSS, vol. 53, no. 1, 1946.

[2] E. E. Altshuler, T. H. O’Donnell, A.D. Yaghjian, and S. R. Best, "A Monopole Superdirective Array", IEEE Transactions on Antennas and Propagation, vol. 53, no. 8, pp. 2653-2661, August 2005.

[3] T. H. O’Donnell, and A. D. Yaghjian, "Electrically Small Superdirective Arrays Using Parasitic Elements", IEEE Antennas and Propagation Society International Symposium 2006, pp. 3111,3114, 9-14 July 2006.

[4] S. Lim, and H. Ling, "Design of Electrically Small Yagi Antenna", Electronics Letters, vol. 43, no. 5, pp. 3-4, 1 March 2007.

[5] A. D. Yaghjian, T. H. O'Donnell, E. E. Altshuler, and S. R. Best "Electrically Small Supergain End-Fire Arrays", Radio Science, vol. 43, 2008.

[6] P. Sharma, D. Arora, and H. Gupta, "Designing Superdirective Patch Antenna Array Using Metamaterial", International Journal of Engineering Research \& Technology (IJERT), vol. 1, issue 8, October 2012.

[7] O. S. Kim, S. Pivnenko, and O. Breinbjerg, "Superdirective Magnetic Dipole Array as a First-Order Probe for Spherical Near-Field Antenna Measurements", IEEE Transactions on Antennas and Propagation, vol. 60, no. 10, pp. 4670-4676, October 2012.

[8] B. Sentucq, A. Sharaiha, and S. Collardey, "Superdirective MetamaterialInspired Electrically Small Antenna Arrays", 7th European Conference on Antennas and Propagation (EuCAP 2013), pp.151,155, 8-12 April 2013.

[9] A. Clemente, M. Pigeon, L. Rudant, and C. Delaveaud, "Design of a Super Directive Four-Element Compact Antenna Array Using Spherical Wave Expansion, IEEE Transactions on Antennas and Propagation, vol. 63, no. 11, pp. 4715-4722, November 2015.

[10] A. Haskou, A. Sharaiha, and S. Collardey, "Design of Small Parasitic Loaded Superdirective End-Fire Antenna Arrays", IEEE Transactions on 
Antennas and Propagation, vol. 63, no. 12, pp. 5456-5464, December 2015.

[11] A. Haskou, A. Sharaiha, and S. Collardey, "Compact Planar Arrays Based on Parasitic Superdirective Elements", 10th European Conference on Antennas and Propagation (EuCAP 2016), Davos, Switzerland, 10-15 April 2016.

[12] ANSYS HFSS, Pittsburg, PA 15219, USA.

[13] [Online]. Available: www.minicircuits.com/pdfs/ZX10-2-20.pdf

[14] [Online]. Available: http://www.datasheetarchive.com/dl/Scans-060/ DSA2IH0075492.pdf

[15] [Online]. Available: http://docs-europe.electrocomponents.com/ webdocs/12a7/0900766b812a766a.pdf 